\title{
ANALISIS FASILITAS KERJA DENGAN PENDEKATAN ERGONOMI REBA DAN RULA DI PERUSAHAAN CV.ANUGERAH JAYA
}

\author{
Ellaury Chanty \\ Teknik Industri, Fakultas Teknik \\ Universitas Maarif Hasyim Latif, Sidoarjo, Indonesia \\ e-mail: ellaury-chanty@student.umaha.ac.id
}

\begin{abstract}
ABSTRAK
Fasilitas kerja didalam perusahaan menjadi hal yang harus diutamakan guna menunjang kesuksesan dan peningkatan produktivitas. Pada saat ini proses produksi dalam perusahaan CV. Anugerah Jaya masih menggunakan mesin dan peralatan yang manual sehingga karyawan yang bekerja didalamnya merasakan sakit pada bagian tubuh saat melakukan pekerjaan setiap harinya. Dengan mendapatkan data melalui kuesioner nordic body map untuk mengetahui keluhan pada bagian tubuh yang sakit, diketahui prosentase terbesar pada bagian pengeleman sebesar $83 \%$ dan bagian pemotongan kartonsebesar 100\%.Penyebab keluhan sakit kemudian dianalisis dengan menggunakanpendekatan ergonomi metode RULA dan REBA dengan pengukuran sudut derajat postur tubuh menggunakan aplikasi autocad. Padanilai REBA menunjukan 10 yang berarti postur tubuh saat bekerja memerlukan perubahan secepatnya, sedangkan nilai RULA menunjukan actionLevel 3, dengan skor akhir nilaitotal 5 sampai 6 nilai yaitu perlu investgasi lebih lanjut dan dilakukan perubahan segera.Setelah didapati hasil dari RULA dan REBA fasilitas kerja produksi direkomendasikan untuk mengurangi keluhan sakit karyawan bekerja.
\end{abstract}

Kata kunci: fasilitas kerja, nordic body map, rula reba

\section{PENDAHULUAN}

Karton merupakan material yang terbuat dari pulp, baik pulp organik, pulp sintetis atau sisa produksi kertas (daur ulang) Pembuatan produk karton membutuhkan tenaga kerja yang ahli didalam bidangnya adapun investasi fasilitas kerja yang diberikan perusahaan guna menunjang proses pembuatan karton.Perlunya pemerhatian terhadap fasilitas kerja yang baik tentunya akan menjadikan orang yang bekerja didalamnya menjadi nyaman.

CV.Anugerah Jaya merupakan perusahaan converting yang bergerak dalam bidang kemasan karton yang berada di wilayah Surabaya. Perusahaan ini menyuplai karton untuk sepatu, sandal, keramik, kerupuk dan sebagainya. Proses pembuatan karton dalam perusahaan CV.Anugerah Jaya menggunakan mesin manual dan fasilitas kursi kecil untuk bekerja sehingga seringkali karyawan yang bekerja diarea produksi mengeluhkan rasa sakit, pegal, kesemutan dan izin dikarenakan tidak enak badan.Penyesuaian tempat bekerja yang ergonomis diharapkan dapat memberikan kenyamanan, keamanan dan membuat orang yang bekerja didalamnya menjadi betah sehingga produktivitas kerjanya meningkat. Menurut penelitian Puspita, Partiwi dan Rahman (2011) performansi ergonomi keselamatan dan kesehatan kerja terhadap kinerja perusahaan, memberikan pengetahuan mengenai penyebab menurunnya performansi ergonomi K3 terhadap kinerja perusahaan dan membantu perusahaan dalam meningkatkan performansi ergonomi K3 terhadap kinerja perusahaan. Menurut Prasnowo, Sajiyo (2017). Mendesain ulang Lingkungan Kerja dengan pendekatan Ergonomi dapat mengurangi kelelahan dari kategori "Sangat Lelah" menjadi "Tidak Lelah" menurunkan gangguan muskuloskeletal "Sangat Gangguan" menjadi "Tidak Mengganggu", dan dapat meningkatkan output produksi

Dalam lingkungan kerja fasilitas kerja perlu diperhitungkan perusahaan agar dirancang ulang dengan lebih baik dan cukup untuk memperbaiki postur gerak tubuh karyawan pada saat bekerja. Agar fasilitas kerja dapat sesuai dengan pekerjaan yang diberikan perusahaan, makaperlu dilakukannya sebuah perbaikan fasilitas kerja yang ergonomi dengan menggunakan pendekatan ergonomi REBA dan RULA.

\section{METODE PENELITIAN}

\section{Ergonomi}

Pengertian ergonomi menurut Wignjosoebroto, (2008) yaitu ilmu yang sistematis mengenai kemampuan dan keterbatasan manusia dalam 
merancang sistem kerja tujuan ergonomi ialah sebagai terciptanya keseimbangan rasional dari aspek ekonomi maupun aspek antropologis.

\section{Postur Tubuh dan Gerakan}

Postur tubuh saat bekerja yang baik dapat dilihat darigerakan organ tubuh saat bekerjagerakan yang dilakukan meliputi: flexion yakni posisi diantara dua tulang mengalami pengurangan sudut, extension yakni posisi merentangkan dimana terjadi peningkatan sudut antara dua tulang, abduction yakni posisi menyamping menjauh dari tengah tubuh, adduction bergerak kearah tengah tubuh, rotatio nyakni posisi perputaran pada bagian atas lengan atau bagian kaki depan, pronation yakni posisi perputaran bagian tengah menuju kedalamdan supination yakni posisi perputaran kearah samping menuju luar

\section{Rapid Entire Body Assessment (REBA)}

REBA dipilih untuk menilai posisi sikap kerja berdiri pada setiap bagian tubuh seorang saat bekerja, dengan dipengaruhi faktor coupling, (beban eksternal pada saat bekerja). Metode ini menjadi bentuk analisa subyektif seluruh bagian tubuh pekerja (Hignett \& McAtamney, 2000). Untuk menilai sikap kerja pada saat berdiri hal ini dilakukan dengan mendapatkan foto atau video saat bekerja, kemudian dilakukan perhitungan REBA pada bagian tubuh grup A yaitu neck(leher), trunk(batang tubuh), dan leg(kaki) dan grup B seperti upper arms,(lengan atas) lower arms,(lengan bawah) dan wrist(pergelangan tangan) kemudian score pada setiap grup ditambahkan. Score paling tinggi akan menghasilkan resiko tinggi sakit pada tubuh dan mengharuskan posisi sikap kerja diubah.

\section{Rapid Upper Limb (RULA)}

RULA dijelaskan sebagai metode ergonomi dengan menilai posisi sikap kerja pada posisi duduk Dockrell et al., (2012). RULA digunakan sebagai evaluasi atau penilaian yang subyektif terhadap posisi sikap kerja terhadap faktor resiko sakit atau keluhan yang akan dialami seseorang saat bekerja. Dibandingkan dengan REBA, metode RULA lebih detail terhadap pergerakan otot

\section{Nordic Body Map}

Nordic body map yakni alat berbentuk kuesioner untuk mengukur tingkat ketidaknyamanan atau sakit pada bagian daerah tubuh Elbert, Kroemer, \& Hoffman, (2018). Sasaran kuesioner ini yaitu mengetahui gangguan kesehatan seperti MSDs (gangguan otot) berdasarkan keluhan sampel (pekerja). Sifatnya sangat subyektif karena berdasarkan persepsi pekerja yang merasakan gangguan MSDs (gangguan otot). Nordic body map menyediakan format standar untuk pengumpulan data mengenai masalah musculoskletal. Data yang ada digunakan untuk menunjukan bagian spesifik yang tidak nyaman dari tubuh.

\section{HASIL DAN PEMBAHASAN}

Perusahaan CV. Anugerah Jaya adalah perusahaan yang terletak di daerah Warugunung Kecamatan Karang pilang, Surabaya. Yang berdiri sejak tahun 2014.

\section{Diagram Proses Produksi}

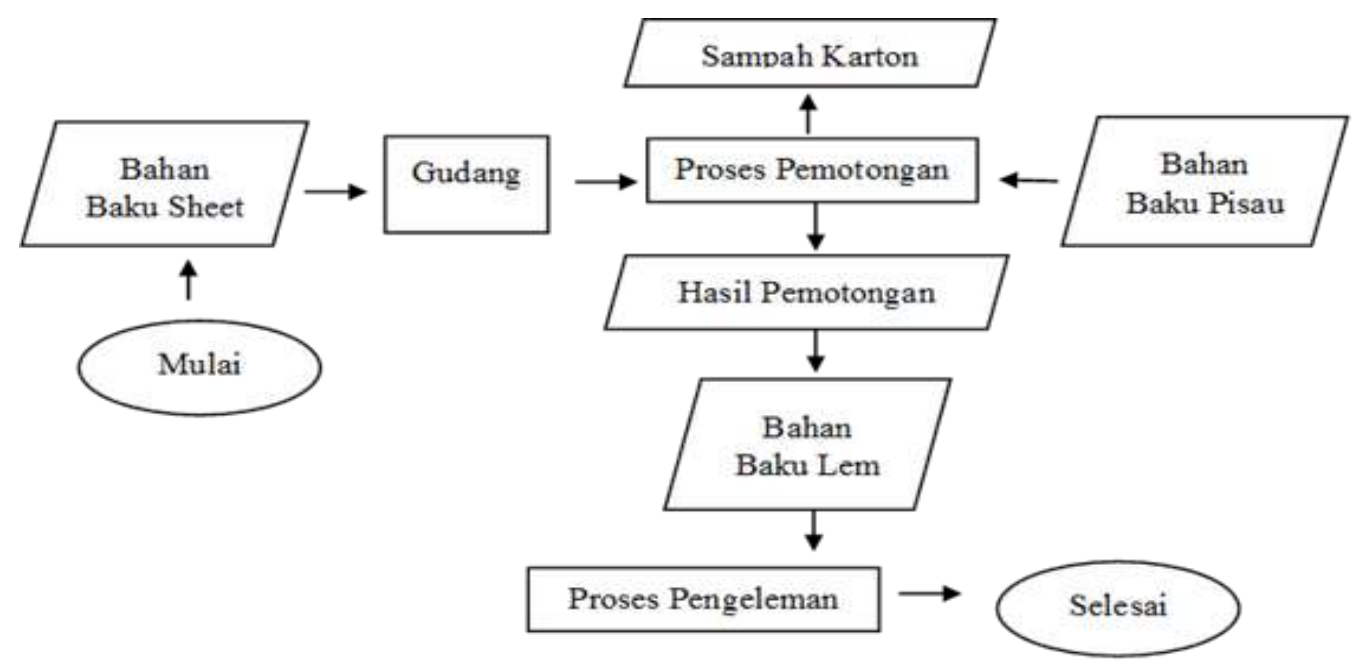

Gambar. 1 Diagram Proses Produksi 


\section{AnalisisKuesioner Nordic Body Map}

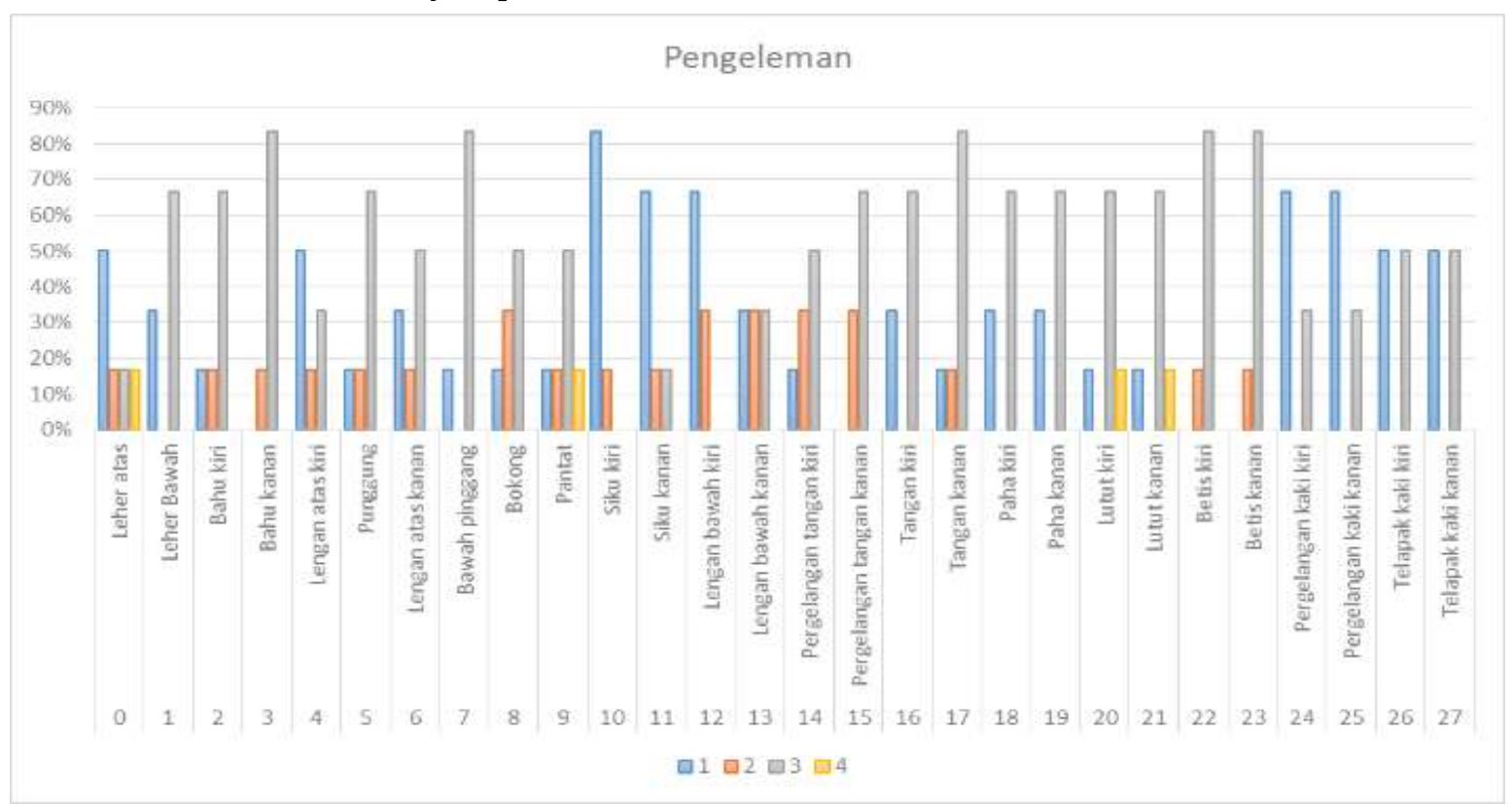

Gambar. 2 Grafik Prosentase Keluhan Bagian Pengeleman Karton

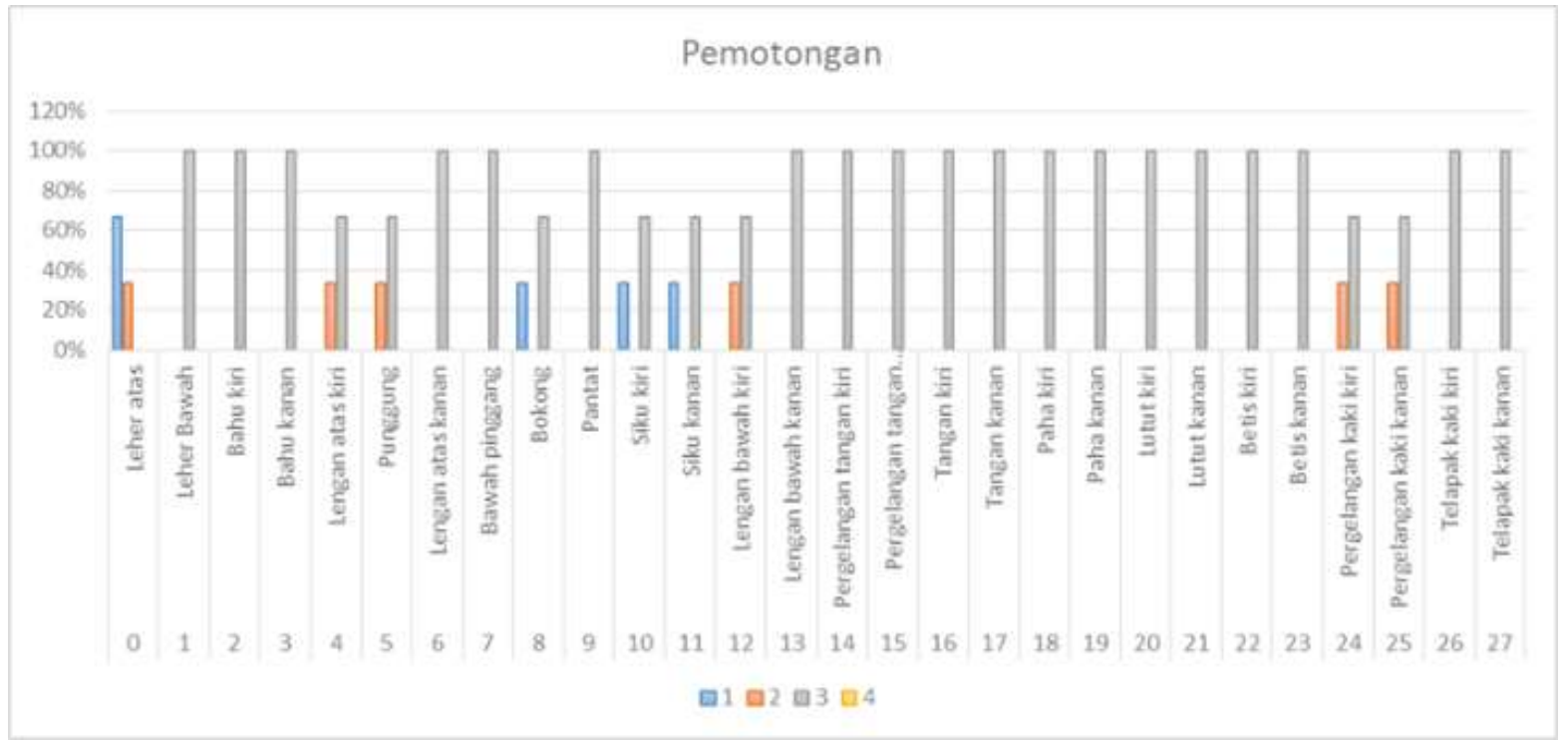

Gambar. 3 Grafik Prosentase Keluhan Bagian Pemotongan Karton 
Berdasarkan gambar 2 grafik diatas dapat diketahui keluhan pada setiap anggota tubuh pada bagian pengeleman karton. terdapat keluhan terbesar pada daerah betis kanan, betis kiri, tangan kanan, bawah pinggang dan bahu kanan sebesar $83 \%$

Berdasarkan gambar 3 grafik diatas dapat diketahui keluhan pada setiap anggota tubuh padabagian pemotongan karton terdapat keluhan

\section{AnalisisSudut Software Autocad}

Tabel.1 Pengukuran Sudut Derajat Postur Tubuh

\begin{tabular}{|c|c|c|c|}
\hline \multicolumn{4}{|c|}{ Karyawan } \\
\hline No & $\begin{array}{l}\text { Gambar } \\
\text { tubuh }\end{array}$ & Bagian & Keterangan \\
\hline 1. & & Leher & $\begin{array}{l}\text { Terdapat } \\
\text { sudut } 47^{0} \text { pada } \\
\text { gambar leher } \\
\text { menunduk } \\
\text { melihat } \\
\text { kebawah }\end{array}$ \\
\hline 2. & & Tubuh & $\begin{array}{l}\text { Terdapat } \\
\text { sudut } 46^{0} \text { pada } \\
\text { gambar tubuh } \\
\text { yang } \\
\text { membengkok } \\
\text { melihat } \\
\text { kebawah }\end{array}$ \\
\hline 3. & & Kaki & $\begin{array}{l}\text { Terdapat } \\
\text { sudut } 154^{0} \\
\text { pada gambar } \\
\text { kaki }\end{array}$ \\
\hline 4. & & $\begin{array}{l}\text { Lengan } \\
\text { bagian } \\
\text { atas }\end{array}$ & $\begin{array}{l}\text { Terdapat } \\
\text { sudut } 33^{0} \text { saat } \\
\text { operator } \\
\text { membawa } \\
\text { barang }\end{array}$ \\
\hline 5. & & $\begin{array}{l}\text { Lengan } \\
\text { bagian } \\
\text { bawah }\end{array}$ & $\begin{array}{l}\text { Terdapat } \\
\text { sudut } 40^{0} \text { saat } \\
\text { operator } \\
\text { membawa } \\
\text { barang }\end{array}$ \\
\hline
\end{tabular}

terbesar pada daerah leher bawah, bahu kiri, bahu kanan, lengan kanan, lengan atas kanan, bawah pinggang, lengan bawah kanan, pergelangan tangan kiri, pergelangan tangan kanan , tangan kiri, tangan kananm paha kiri, paha kanan, lutut kiri, lutut kanan, betis kiri betis kanan, telapak kaki kiri, telapak kaki kanan sebesar $100 \%$

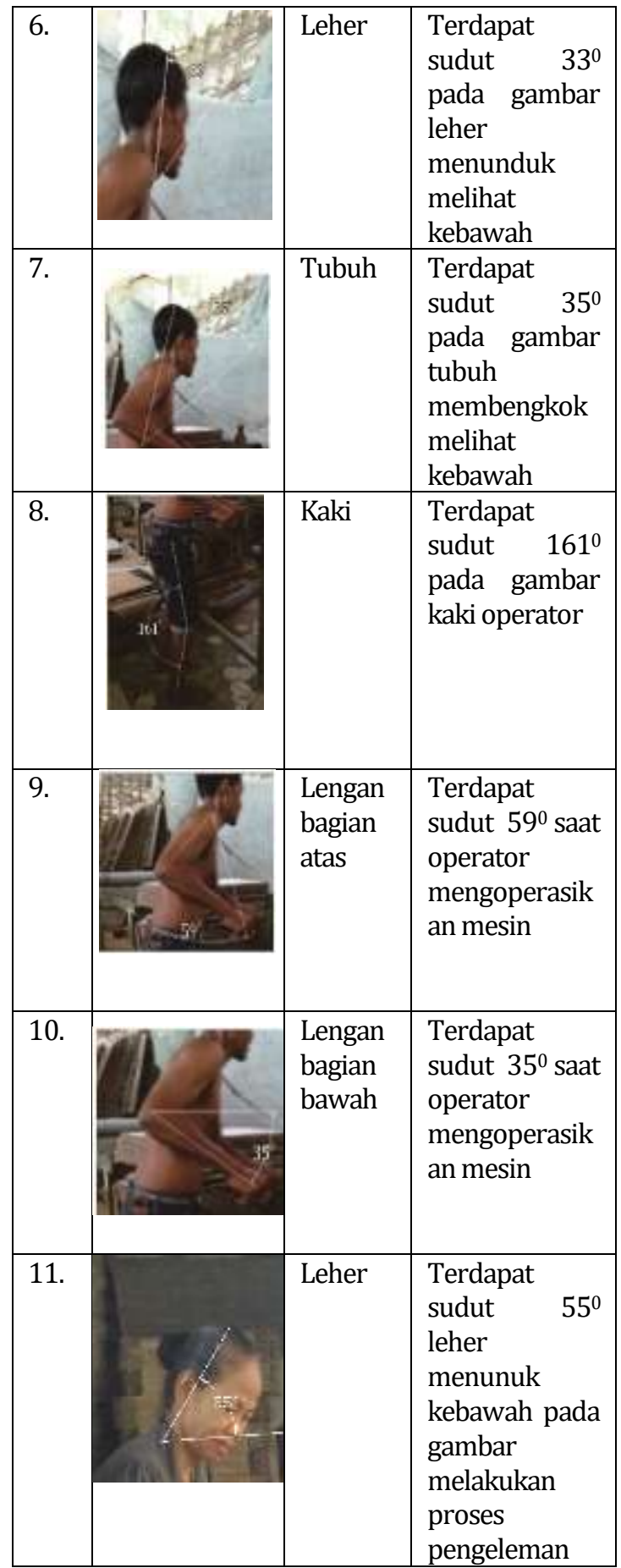




\begin{tabular}{|c|c|c|}
\hline 12. & Tubuh & $\begin{array}{l}\text { Terdapat } \\
\text { sudut } 32^{0} \text { pada } \\
\text { gambar tubuh } \\
\text { bengkok } \\
\text { melihat } \\
\text { kebawah } \\
\text { melakukan } \\
\text { proses } \\
\text { pengeleman }\end{array}$ \\
\hline 13. & $\begin{array}{l}\text { Lengan } \\
\text { bagian } \\
\text { bawah }\end{array}$ & $\begin{array}{l}\text { Terdapat } \\
\text { sudut } 30^{0} \text { pada } \\
\text { gambar lengan } \\
\text { melakukan } \\
\text { proses } \\
\text { pengeleman }\end{array}$ \\
\hline 14. & $\begin{array}{l}\text { Lengan } \\
\text { bagian } \\
\text { atas }\end{array}$ & $\begin{array}{l}\text { Terdapat } \\
\text { sudut } 48^{0} \text { pada } \\
\text { gambar lengan } \\
\text { atas saat } \\
\text { melakukan } \\
\text { proses } \\
\text { pengeleman }\end{array}$ \\
\hline 15. & Leher & $\begin{array}{l}\text { Terdapat } \\
\text { sudut } \\
\text { leher } \\
\text { menunduk } \\
\text { kebawah pada } \\
\text { gambar } \\
\text { melakukan } \\
\text { proses } \\
\text { pemolesan } \\
\text { lem }\end{array}$ \\
\hline 16. & Tubuh & $\begin{array}{l}\text { Terdapat } \\
\text { sudut } \\
\text { tubuh } \\
\text { bengkok } \\
\text { melihat } \\
\text { kebawah pada } \\
\text { gambar } \\
\text { melakukan } \\
\text { proses } \\
\text { pemolesan } \\
\text { lem }\end{array}$ \\
\hline 17. & $\begin{array}{l}\text { Lengan } \\
\text { bagian } \\
\text { atas }\end{array}$ & $\begin{array}{l}\text { Terdapat } \\
\text { sudut } \\
\text { tubuh } \\
\text { bengkok } \\
\text { melihat } \\
\text { kebawah pada } \\
\text { gambar } \\
\text { melakukan } \\
\text { proses } \\
\text { pemolesan } \\
\text { lem }\end{array}$ \\
\hline
\end{tabular}

\begin{tabular}{|c|c|c|}
\hline 18. & $\begin{array}{l}\text { Lengan } \\
\text { bagian } \\
\text { bawah }\end{array}$ & $\begin{array}{l}\text { Terdapat } \\
\text { sudut } \\
\text { tubuh } \\
\text { bengkok } \\
\text { melihat } \\
\text { kebawah pada } \\
\text { gambar } \\
\text { melakukan } \\
\text { proses } \\
\text { pemolesan } \\
\text { lem }\end{array}$ \\
\hline
\end{tabular}

\section{Analisis RULA \& REBA Software Ergofellow}

Berdasarkan hasil REBA gerakan postur tubuh saat bekerja operator menunjukan hasil penilaian 10 dengan leher dan badan menekuk lebih dari 20 derajat, ditopang oleh 2 kaki tekukan lebih dari 60 derajat, berat saat melakukan pemotongan lebih dari $5 \mathrm{Kg}$. Sedangkan lengan atas berada didalam 45 sampai 90 derajat mengalami abduction dan lengan bawah berada pada titik 0 sampai 60 derajat atau lebih dari 100 derajat dengan aktivitas satu atau lebih bagian tubuh menahan lebih lama dari 1 menit, dan kopling baik dengan hasil score 10 postur tubuh saat bekerja selama ini mempunyai resiko yang tinggi dan seharusnya perlu adanya tinjau segera agar perbaikan dapat mengurangi tingkat sakit bekerja.

Berdasarkan hasil RULA diatas gerakan postur tubuh saat bekerja operator menunjukan hasil penilaian 6 dari action level 3 dengan leher menekuk kurang dari 20 derajat, badan menekuk dari 20 sampai 60 derajat, lengan atas berada didalam 45 sampai 90 derajat mengalami abduction dan lengan bawah berada pada titik 0 sampai 60 derajat, postur kaki balance, dengan aktivitas otot grup A dan grup B satu atau lebih bagian tubuh menahan lebih lama mulai dari 1 menit kemudian diulangi lebih dari 4 kali permenit. Beban pada grup A dan grup B lebih daro $2 \mathrm{~kg}(4.4 \mathrm{lb})$ dengan score ahir RULA 6 dan action level 3, Dapat diartikan level 3 adalah memerlukan investigasi dan perubahan postur kerja harus dilakukan secepatnya.

Berdasarkan hasil REBA gerakan postur tubuh saat bekerja membawa barang operator menunjukan hasil penilaian 10 dengan leher dan badan menekuk lebih dari 20 derajat, ditopang oleh 2 kaki tekukan lebih dari 60 derajat, berat saat membawa barang lebih dari5Kg. Sedangkan lengan atas berada didalam 20 sampai 45 derajat mengalami abduction dan lengan bawah berada pada titik 0 sampai 60 derajat atau lebih dari 100 derajat dengan aktivitas satu atau lebih bagian tubuh menahan lebih lama dari 1 menit, dan kopling baik dengan hasil score 10 postur tubuh saat bekerja selama ini mempunyai resiko yang tinggi dan seharusnya perlu adanya tinjau segera agar perbaikan dapat mengurangi tingkat sakit bekerja

Berdasarkan hasil RULA gerakan postur tubuh saat bekerja operator menunjukan hasil penilaian 6 dari 
action level 3 dengan leher menekuk kurang dari 20 derajat, badan menekuk dari 20 sampai 60 derajat, lengan atas berada didalam 45 sampai 90 derajat mengalami abduction dan lengan bawah berada pada titik 0 sampai 60 derajat, postur kaki balance, dengan aktivitas otot grup A dan grup B satu atau lebih bagian tubuh menahan lebih lama mulai dari 1 menit kemudian diulangi lebih dari 4 kali permenit. Beban pada grup A dan grup B lebih dari $2 \mathrm{~kg}$ ( $4.4 \mathrm{lb}$ ) dengan score RULA 6 dan action level 3, Dapat diartikan level 3 adalah memerlukan investigasi dan perubahanpostur kerja harus dilakukan secepatnya.

\section{Rekomendasi Fasilitas Kerja Ergonomi}

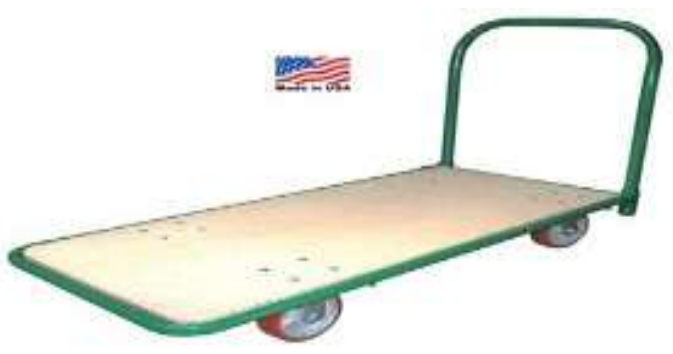

Gambar.8 Resin Platform Truck

Rekomendasi fasilitas kerja ergonomi mengganti pekerjaan operator yang memindahkan barang dari gudang ke pabrik gudang dan dipindahkan secara manual, kelebihan fasilitas resin platform truck daripadagerobak modifikasi yaitu kapasitas muat yang banyak, tahan lama juga mudah dalam penggunaannya.

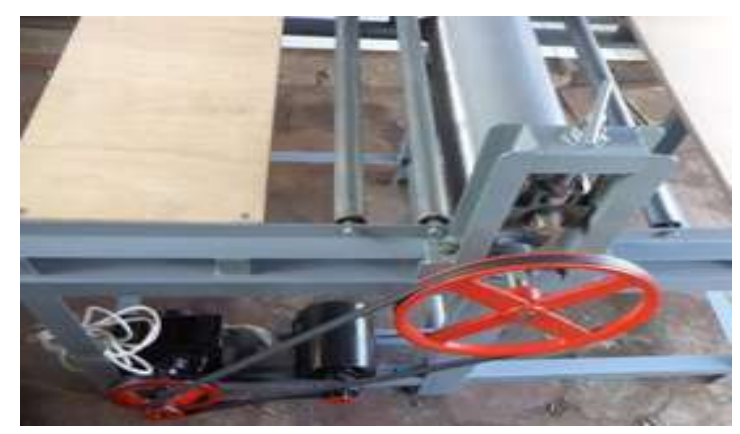

Gambar.9 Mesin Plong Tenaga Motor

Rekomendasi fasilitas kerja proses pemotongan karton dari menggunakan penggilingan dengan tenaga manusia yaitu menggunakan mesin yang sama namun dimodifikasi ulang dengan menggunakan motor/dinamo penggerak 1/4 HP listrik 900VA ato $1 / 2$ HP 1300VA sesuai kebutuhan produksinya. mesin tidak bersuara keras ,ukuran standart lebar Roll $60 \mathrm{~cm}$.

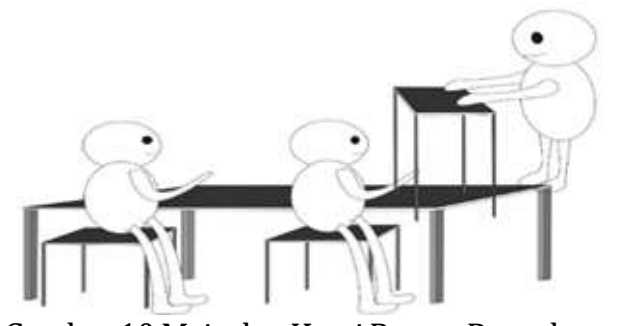

Gambar.10 Meja dan Kursi Proses Pengeleman

Sedangkan rekomendasi fasilitas pada proses mengelem produk yang sebelumnya duduk dikursi plastik mini menjadi ditambahkan beberapa kursi dan meja agar operator yang bekerja tidak perlu membungkuk dan dapat bekerja dengan nyaman

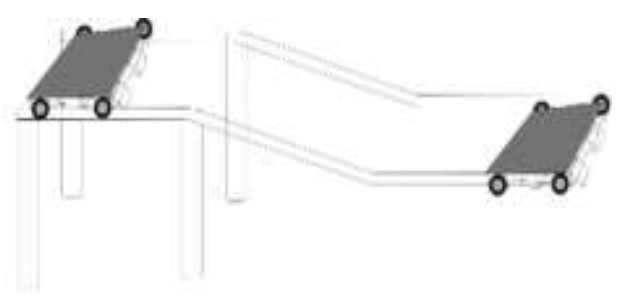

\section{Gambar.11 Papan Besi Roll dan Roda}

Adapun Rekomdendasi lain untuk membawa hasil potongan karton yaitu dengan menggunakan alat bantu papan besi roll dan roda yang dapat mengganti fungsi conveyer mengantarkan kepada bagian pengeleman karton.

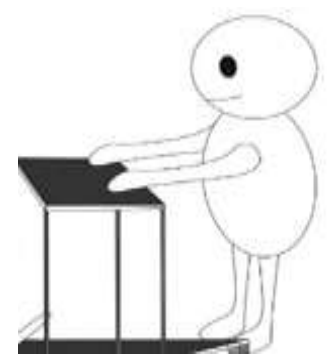

Gambar 12. Meja berdiri untuk Proses Memoles lem

Metode ini memudahkan pekerjaan dengan berdiri, Proses dari conveyer akan langsung mengarah pada proses pengeleman, cara ini menjadikan pekerjaan cepat dan mudah.

\section{PENUTUP}

Pada tingkat resiko dapat dijabarkan sebagai berikut:

a. Proses produksi karton CV.Anugerah Jaya adalah pada bagian pemotongan terdapat tingkat resiko yang tinggi yaitu dengan score 10 pada penilaian REBA, diidentifikasi yaitu perlunya dilakukan segera perbaikan ulang pada fasilitas kerja yang digunakan pada saat ini sehingga tidak mengakibatkan karyawan yang bekerja didalamnya merasa tidak nyaman dan sakit saat bekerja. 
b. Sedangkan tingkat resiko pada bagian membawa barang, hasil pada perhitungan REBA didapati score 10 yang berarti resiko tinggi sehingga diperlukannya perbaikan ulang pada fasilitas kerja.

c. Untuk Tingkat resiko pada bagian pengeleman hasil perhitungan RULA yang diperoleh yaitu score 6 dengan action level 3 yang berarti memerlukan investigasi dan perubahan postur kerja harus dilakukan secepatnya.

Pada rekomendasi fasilitas kerja dapat dijabarkan sebagai berikut :

a. Rekomendasi fasilitas kerja pada bagian pemotongan adalah dengan menggunakan mesin bertenaga motor/dinamo penggerak 1/4 HP listrik 900VA ato 1/2 HP 1300VA.

b. Rekomendasi fasilitas kerja pada bagian membawa barang adalah dengan menggunakan Resin Platform Truck dengan papan yang terbuat dari besi sehingga dapat digunakan dalam jangka waktu yang lama, dan mudah untuk dibawa karena dimensi resin platform truck lebih kecil daripada gerobak modifikasi yang dipakai saat ini.

c. Rekomendasi fasilitas kerja pada bagian pengeleman yaitu berupa meja dan kursi duduk agar karyawan yang bekerja didalamnya tidak mengalami kesemutan. Meja dan kursi yang dibuat dari kayu akan bertahan kurang lebih 3 tahun saat pemakaian.

\section{DAFTAR PUSTAKA}

Dockrell, S., O'Grady, E., Bennett, K., Mullarkey, C., Mc Connell, R., Ruddy, R., ... Flannery, C. (2012). An investigation of the reliability of Rapid Upper Limb Assessment (RULA) as a method of assessment of children's computing posture. Applied Ergonomics, 43(3), 632-636.

Elbert, K. K., Kroemer, H. B., \& Hoffman, A. D. K. (2018). Ergonomics: how to design for ease and efficiency. Academic Press.

Hignett, S., \& McAtamney, L. (2000). Rapid entire body assessment (REBA). Applied Ergonomics, 31(2), 201-205.

Prasnowo, M. A., Sajiyo (2017). Redesign of envitomental work with ergonomic intervention to reduce fatigue and increase TO R EDUCE F ATIGUE AND I NCREASE, 4(c), 219-221.

Puspita, A. D., Partiwi, S. G. and Rahman, A. (2011) 'Perancangan model penaksiran performasi ergonomi terhadap kinerja perusahaan ( Studi Kasus : PT . PAL INDONESIA )'.

Wignjosoebroto, S. (2008). Ergonomi, Studi Gerak \& waktu. Penerbit Guna Widya, Jakarta. 